ORIGINAL ARTICLE

\title{
Work factors as predictors of intense or disabling low back pain; a prospective study of nurses' aides
}

\author{
W Eriksen, D Bruusgaard, S Knardahl
}

Occup Environ Med 2004;61:398-404. doi: 10.1136/oem.2003.008482

\begin{abstract}
See end of article for authors' affiliations

Correspondence to: Dr W Eriksen. Department of General Practice and Community Medicine, University of Oslo, PÓ Box 1130 Blindern, 0318 Oslo. Norway; w.b.eriksen@ samfunnsmed.vio.no
\end{abstract}

Accepted 21 July 2003

\begin{abstract}
Aims: To identify the work factors that predict intense low back pain (LBP) and LBP related sick leaves in nurses' aides.

Methods: The sample comprised 4266 randomly selected Norwegian nurses' aides, not bothered or only a little bothered by LBP during the previous three months, and not on sick leave when completing a mailed questionnaire in 1999. Of these, 3808 (89.3\%) completed a second questionnaire 3 months later and $3651(85.6 \%)$ completed a third questionnaire 15 months later. Intensity of low back symptoms and certified sick leaves attributed to LBP during the observation period were assessed by self reports at the follow ups.

Results: After adjustments for LBP during the three months prior to baseline, baseline health complaints, demographic and familial factors, and a series of physical, psychological, and social work factors, logistic regression analyses revealed the following associations: intense low back symptoms were predicted by frequent positioning of patients in bed, perceived lack of support from immediate superior, and perceived lack of pleasant and relaxing culture in the work unit. LBP related sick leaves were predicted by frequent handling of heavy objects, medium level of work demands, perceived lack of supportive and encouraging culture in the work unit, working night shifts, and working in a nursing home. Long term LBP related sick leaves were associated with changes of work or work tasks during the observation period that resulted in a perceived reduction of support and encouragement at work.

Conclusions: Not only frequent mechanical exposures, but also organisational, psychological, and social work factors, such as night shift work, perceived lack of support from superior, and perceived lack of a pleasant and relaxing or supporting and encouraging culture in the work unit, are associated with an increased risk of intense low back symptoms and LBP related sick leaves in nurses' aides.
\end{abstract}

S tudies from around the world have documented the enormous burden of low back pain (LBP) to individuals and society. ${ }^{1}$ Nurses' aides, doing both emotional and heavy physical work, and being exposed to a combination of mechanical and psychosocial stress at work, are one of the occupational groups that are most frequently affected by LBP. $^{2-4}$

A large number of studies have explored the relation between work factors and LBP, in both nursing personnel and other occupational groups. ${ }^{5-8}$ Heavy lifting, frequent twisting and bending, whole body vibration, low social support at work, and low job satisfaction have been consistently associated with the risk of LBP. In most studies, however, the intensity and the functional consequences of the pain were not reported. Hence, it may be difficult to tell whether the identified predictors are predictors of "humdrum nuisance" or severe disease.

The relation between mechanical exposures at work and the occurrence of LBP related sickness absence was reported in several studies, with a majority of positive associations. ${ }^{3-15}$ The relation of social and psychological work factors to the occurrence of LBP related sick leaves has been explored in some studies, but not in nursing personnel, and with inconsistent results. ${ }^{12}{ }^{14-16}$ Little is known of how work factors are related to the occurrence of LBP related sick leaves that last for several weeks.

The objective of the present study was to identify the work factors that predict intense LBP and LBP related sick leaves in nurses' aides. The effects of a wide spectrum of physical, psychological, and social work factors were explored in a prospective design.

\section{METHODS \\ Subjects}

Assistive nursing personnel in Norway include a large group of certified nurses' aides and a smaller group of unlicensed nurses' aides, who have no formal training and often hold temporary jobs. The number of vocationally active nurses' aides was estimated as approximately 55000 in 1999 (Norwegian Union of Health and Social Workers, personal communication). About 50000 of these, mainly certified nurses' aides, were members of the Norwegian Union of Health and Social Workers (the Union).

During the last week of October 1999, 12000 nurses' aides were randomly selected from the Union's member list, and were mailed a questionnaire. After one reminder, $7478(62.3 \%)$ consented to participate in the study and completed the questionnaire. The list of members also includes retired persons, and contacts over the telephone during the data collection gave the impression that nonworking individuals were not motivated for participating in the study. Hence, the true response rate of the vocationally active subjects was probably higher than the overall response rate.

The criteria for inclusion in the present study were: (1) having filled in and returned the questionnaire at baseline; (2) working more than 18 hours per week-that is, more than half-time job; (3) not on leave because of illness or pregnancy at baseline; and (4) not bothered or only a little bothered by LBP during the three months prior to baseline. The 4266 nurses' aides who fulfilled these criteria comprised the sample of the study. Of these, 3808 (89.3\%) completed a second questionnaire three months later and 3651 (85.6\%) 


\section{Main messages}

- Not only frequent mechanical exposures, but also organisational, psychological, and social work factors, such as night shift work, perceived lack of support from superior, and perceived lack of a pleasant and relaxing or supporting and encouraging culture in the work unit, are risk factors of intense low back symptoms and low back pain related sick leaves in nurses' aides.

completed a third questionnaire 15 months later. Figure 1 shows the selection process in a flow chart.

\section{Outcome measures}

At the three month follow up (as at baseline), the nurses' aides were asked the extent to which they had been bothered by LBP during the previous three months. Optional answers were "not bothered by LBP", "a little bothered by LBP", "rather intensely bothered by LBP", and "very intensely bothered by LBP". The nurses' aides were also asked whether they had been absent from work because of illness for more than three days in a row during the previous three months (in Norway, certification from a physician is needed when the absence lasts longer than three days). Those who answered "yes" were asked about the cause of the absence, and invited to mark on a checklist one or several of the following alternatives: "airway infection (cold, flue, sinusitis, etc)", "headache", "neck pain", "upper back pain", "low back pain", "pain in the shoulder, arm, or hand", "pain in the hip, leg, or foot", and "other disease or illness". The questions were supplemented by a pain region drawing, in which the low back was defined as the region between the 12. ribs and the gluteal folds.

At the 15 month follow up, the nurses' aides were asked whether they had been absent from work because of illness for more than 14 days in a row and for more than eight weeks in a row during the previous 12 months. Those who answered "yes" were asked to mark on check lists the cause of the absence, guided by a pain region drawing.

The outcome measures of the present study were the proportion of subjects who reported at the three month follow up that they had been intensely (that is, rather intensely or very intensely) bothered by LBP, the proportion of subjects who reported at the three month follow that they had had LBP related sick leaves lasting longer than three days, the proportion of subjects who reported at the 15 month follow that they had had LBP related sick leaves lasting longer than 14 days, and the proportion of subjects who reported at the 15 month follow that they had had LBP related sick leaves lasting longer than eight weeks.

\section{Independent variables}

At baseline, demographic and familial characteristics, work related factors, smoking, physical leisure time activities, and health complaints were recorded, as described in detail elsewhere. ${ }^{17}$

The type of wards in which the subjects were working was recorded by asking "What is your main workplace?". There was a checklist with 12 optional answers.

Exposure to heavy physical work was measured with three questions exploring the frequency of positioning patients in the bed, frequency of lifting or supporting patients manually between bed and chair, and frequency of lifting, carrying, or pushing heavy objects, such as heavy furniture and equipment. The first two questions were translations of questions

\section{Policy implications}

- It is essential that leaders in the health services are supportive, and that they put more emphasis on creating a pleasant and relaxing, and encouraging and supportive culture in their work units.

developed and validated by British scientists. ${ }^{18}$ The subjects were also asked to what extent their job required physical endurance.

Psychological, social, and organisational work factors were measured with scales of the General Nordic Questionnaire for Psychological and Social Factors at Work, "QPSNordic". ${ }^{19}$ There were questions exploring quantitative job demands, positive challenges in the job, role conflicts at work, control at work, social support at work, fairness of the immediate superior's leadership, the organisational culture of the work unit, rewards for good work, threats or violence at work, harassment at work, personal commitment to the work unit, and mastery of work. The responses were scored on Likert five point frequency scales. The multi-item factors were expressed as quintiles of the mean of the item scores.

At both follow ups, the respondents were asked whether they had changed work or work tasks after they completed the first questionnaire. At the 15 month follow up, those who had changed work or work tasks were also asked to report what kind of consequences this change had had on their work situation. Optional answers were "more heavy tasks", "less heavy tasks", "higher work pace", "lower work pace", "more encouragement and support", "less encouragement and support", "other consequences", and "no significant consequences".

\section{Ethics}

The research protocol was approved by the Committee for Medical Research Ethics. Informed written consent was given by the responders.

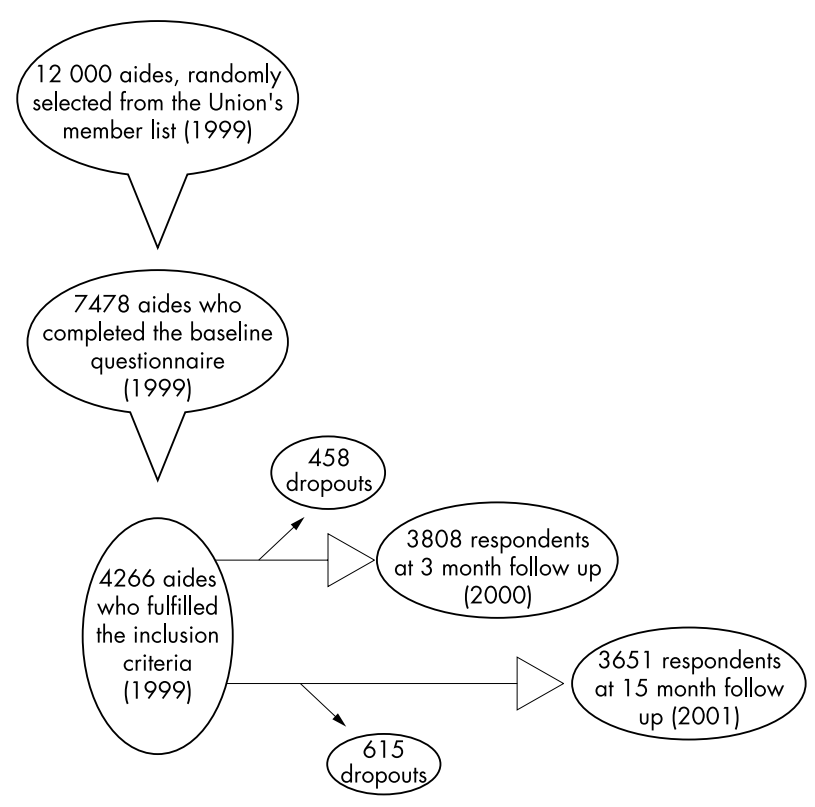

Figure 1 Flow chart of the selection process. 


\section{Statistical analyses}

Statistical analyses were conducted with the Statistical Package for Social Sciences (SPSS), version 6.1. The $\chi^{2}$ test, Fisher's exact test, and logistic regression analysis were used.

The logistic regression models were built in a traditional way, seeking the most parsimonious model that still explains the data, as recommended by Hosmer and Lemeshow. ${ }^{20}$ The variables that were considered as scientifically relevant for the logistic regression models were the work related factors, age, gender, familial characteristics (marital status, number of preschool children, special tasks of caring nature in the leisure time, such as caring for elderly relatives and handicapped children), physical leisure time activities, former smoking, daily consumption of cigarettes, and baseline health complaints. The variables that described the type of ward, for example "working in nursing home", were considered potential candidates for the logistic regression model along with the other work factors, because they reflected aspects of work and exposures that were not fully reflected in the other variables.

Age, gender, and all relevant variables that were related to the dependent variables with a $p$ value below 0.05 in univariate analyses were included in automatic forward stepwise logistic regression analyses. The criteria for inclusion and exclusion during the automatic analytic process were $p=0.05$ and $p=0.10$, respectively, for the overall variables in likelihood ratio tests. When the univariate analyses yield many candidates for the models, as they did in this study, an automatic stepwise procedure may be appropriate. ${ }^{20}$

\section{RESULTS}

\section{Characteristics of respondents and dropouts}

Table 1 shows baseline characteristics of the 4266 nurses' aides who fulfilled the inclusion criteria. The majority were middle-aged, married, or cohabiting women, with no preschool children. Forty one per cent were working in nursing homes.

Subjects who responded at the follow ups (hereafter referred to as respondents) were older, were more often female, were more often non-smokers, and were less bothered by affective symptoms and musculoskeletal pain at baseline than those who responded only to the first questionnaire (data not shown). Respondents also reported less handling of heavy objects at work, less role conflicts at work, less suspicious culture in the work unit, less harassment at work, more fairness in the immediate superior's leadership, and more engagement in the work unit than dropouts. There was no difference between respondents and dropouts with respect to occurrence of LBP during the three months prior to baseline.

\section{Number of cases}

At the three month follow up, 536 (14.1\%) reported that they had been intensely bothered by LBP during the previous three months, whereas $152(4.0 \%)$ reported having had one or several LBP related sick leaves lasting longer than three days. A total of $21.8 \%$ of the respondents who had been intensely bothered, and $1.1 \%$ of those who had not been intensely bothered by LBP had had LBP related sick leaves $(p<0.0001)$. At the 15 month follow up, $228(6.3 \%)$ reported having had one or several LBP related sick leaves lasting longer than 14 days during the previous 12 months, whereas $118(3.3 \%)$ reported having had one or several LBP related sick leaves lasting longer than eight weeks.

\section{Factors related to intense LBP and LBP related sick leaves; univariate analyses}

A series of factors, work factors as well as background factors, were associated with the occurrence of intense LBP
Table 1 Baseline characteristics of the 4266 nurses' aides who fulfilled the inclusion criteria

\begin{tabular}{|c|c|c|}
\hline Characteristics & $\mathbf{n}$ & $\%$ \\
\hline \multicolumn{3}{|l|}{ Age } \\
\hline$<30$ & 341 & 8.0 \\
\hline $30-39$ & 836 & 19.6 \\
\hline $40-49$ & 1777 & 41.7 \\
\hline $50-59$ & 1142 & 26.8 \\
\hline$>59$ & 170 & 4.0 \\
\hline \multicolumn{3}{|l|}{ Gender } \\
\hline Female & 4092 & 96.0 \\
\hline Male & 171 & 4.0 \\
\hline \multicolumn{3}{|l|}{ Marital status } \\
\hline Married or cohabiting & 3404 & 79.9 \\
\hline Single & 857 & 20.1 \\
\hline \multicolumn{3}{|l|}{ Preschool children (<6 y) } \\
\hline 0 & 3622 & 86.6 \\
\hline 1 & 374 & 8.9 \\
\hline 2 or more & 188 & 4.5 \\
\hline \multicolumn{3}{|c|}{$\begin{array}{l}\text { Special tasks of caring nature in the leisure } \\
\text { time (e.g. caring for elderly relatives or } \\
\text { handicapped children) }\end{array}$} \\
\hline No & 3096 & 73.1 \\
\hline A little & 899 & 21.2 \\
\hline Rather much or very much & 242 & 5.7 \\
\hline \multicolumn{3}{|l|}{ Daily consumption of cigarettes } \\
\hline 0 & 2415 & 57.7 \\
\hline $1-9$ & 960 & 22.9 \\
\hline 10 or more & 809 & 19.3 \\
\hline \multicolumn{3}{|l|}{$\begin{array}{l}\text { Physical leisure time activities (at least } \\
20 \text { min once a week) }\end{array}$} \\
\hline No & 1075 & 25.2 \\
\hline Slow walks & 770 & 18.0 \\
\hline Brief walks * & 913 & 21.4 \\
\hline Aerobics or gym * & 260 & 6.1 \\
\hline Other & 1248 & 29.3 \\
\hline \multicolumn{3}{|l|}{ Years as a nurses' aide } \\
\hline$<3$ & 91 & 2.1 \\
\hline $3-9$ & 709 & 16.6 \\
\hline 10 or more & 3463 & 81.2 \\
\hline \multicolumn{3}{|l|}{ Working hours per week } \\
\hline $19-36$ & 3653 & 85.6 \\
\hline$>36$ & 613 & 14.4 \\
\hline \multicolumn{3}{|l|}{ Service sector (main workplace)† } \\
\hline Somatic department (adults) & 550 & 12.9 \\
\hline Psychiatric department (adults) & 324 & 7.6 \\
\hline Paediatric department & 70 & 1.6 \\
\hline Nursing home & 1763 & 41.3 \\
\hline Old people's home & 293 & 6.9 \\
\hline Unit of apartments for old people & 112 & 2.6 \\
\hline Community nurse & 696 & 16.3 \\
\hline Institution for mentally handicapped & 450 & 10.5 \\
\hline Other & 285 & 6.7 \\
\hline \multicolumn{3}{|l|}{$\begin{array}{l}\text { Have ever changed work or work tasks } \\
\text { because of pain }\end{array}$} \\
\hline No & 3746 & 88.0 \\
\hline Yes & 512 & 12.0 \\
\hline \multicolumn{3}{|l|}{ LBP previous 3 months } \\
\hline No & 2235 & 52.4 \\
\hline Yes & 2031 & 47.6 \\
\hline
\end{tabular}

*As the only activity or in combination with slow walks. †The workplace categories are not mutually exclusive, as some subjects reported working in several places.

and LBP related sick leaves in univariate analyses (data not shown). These factors were entered in the forward stepwise logistic regression analyses, and are shown in tables 2-5 (the factors in the final equation as well as the factors that were not retained in the final equation and listed below the bottom line).

\section{Predictors of intense LBP; multivariate analyses}

A forward stepwise logistic regression analysis showed that intense LBP was predicted by positioning patients in bed 5-9 times per average shift, having one preschool child, being much engaged in special tasks of caring nature during the leisure time (for example, caring for handicapped children or 
Table 2 Factors at baseline that predicted intense LBP during the successive three months

\begin{tabular}{|c|c|}
\hline Characteristics at baseline & Odds ratio $(95 \% \mathrm{Cl})$ \\
\hline \multicolumn{2}{|c|}{$\begin{array}{l}\text { Positioning patients in the bed (per average } \\
\text { shift) }\end{array}$} \\
\hline 0 & 1.00 \\
\hline $1-4$ & $1.27(0.91$ to 1.78$)$ \\
\hline $5-9$ & $1.63(1.14$ to 2.31$)$ \\
\hline$\geqslant 10$ & $1.26(0.83$ to 1.91$)$ \\
\hline \multicolumn{2}{|l|}{ Support from immediate superior } \\
\hline 1 (lowest quintile) & 1.00 \\
\hline 2 & 0.60 (0.44 to 0.83$)$ \\
\hline 3 & 0.59 (0.39 to 0.87$)$ \\
\hline 4 & $0.71(0.49$ to 1.02$)$ \\
\hline 5 & $0.75(0.52$ to 1.09$)$ \\
\hline \multicolumn{2}{|c|}{ Relaxing and pleasant culture in the work unit } \\
\hline Not at all/very little & 1.00 \\
\hline Rather little & $0.46(0.24$ to 0.89$)$ \\
\hline Some & $0.54(0.31$ to 0.96$)$ \\
\hline Rather much & $0.65(0.37$ to 1.15$)$ \\
\hline Very much & $0.79(0.43$ to 1.45$)$ \\
\hline \multicolumn{2}{|l|}{ Number of preschool children } \\
\hline 0 & 1.00 \\
\hline 1 & 1.64 (1.16 to 2.31$)$ \\
\hline$\geqslant 2$ & $1.02(0.58$ to 1.79$)$ \\
\hline \multicolumn{2}{|c|}{$\begin{array}{l}\text { Special tasks of caring nature in the leisure } \\
\text { time (e.g. caring for elderly relatives or } \\
\text { handicapped children) }\end{array}$} \\
\hline No & 1.00 \\
\hline A little & $0.82(0.62$ to 1.09$)$ \\
\hline Rather much or very much & 1.58 (1.03 to 2.42$)$ \\
\hline \multicolumn{2}{|l|}{ LBP previous 3 months } \\
\hline No & 1.00 \\
\hline Yes & $3.39(2.61$ to 4.40$)$ \\
\hline \multicolumn{2}{|l|}{ Widespread pain } \\
\hline No & 1.00 \\
\hline Yes & 1.67 (1.30 to 2.14$)$ \\
\hline \multicolumn{2}{|l|}{ Intensity of musculoskeletal pain (any) } \\
\hline No & 1.00 \\
\hline A little & 2.45 (1.29 to 4.65$)$ \\
\hline Rather intense & 3.75 (1.95 to 7.21$)$ \\
\hline Very intense & 3.49 (1.72 to 7.03$)$ \\
\hline \multicolumn{2}{|l|}{ Fatique/fitness } \\
\hline Always or usually fit & 1.00 \\
\hline Varied between fit and fatigued & $1.49(1.14$ to 1.96$)$ \\
\hline Usually or always fatigued & $1.58(1.09$ to 2.28$)$ \\
\hline
\end{tabular}

The final equation in a forward stepwise logistic regression analysis, with likelihood ratio test was used as the criterion for determining variables to be removed from the model. $n=2982$.

The overall rate of correct classification of the dependent variable (predicted outcome compared with the observed outcome) was estimated as $86.18 \%$.

The factors not retained in the final equation were age, gender, number of years the subject had been working as a nurses' aide, level of affective symptoms, sleep complaints, long term health problems of any kind, having (ever) changed work or work tasks because of pain, working in a nursing home, the extent to which the work required physical endurance, frequency of liffing and supporting patients manually between bed and chair, frequency of handling heavy objects at work, quantitative work demands, level of influence on decisions at work, level of control over work pace, level of role conflicts at work, fairness of the immediate superior's leadership, the extent of supportive and encouraging culture in the work unit, rewards for good work, exposure to bullying at work, and level of commitment to the work unit.

elderly relatives), having had LBP during the three months prior to baseline, and having had musculoskeletal pain of any kind, widespread pain, and fatigue during the 14 days prior to baseline (table 2). The upper four quintiles of perceived support from immediate superior (index) were associated with, or tended to be associated with lower odds of intense LBP than the lowest quintile. The lowest quintile, hereafter referred to as "perceived lack of support from immediate superior", is therefore a predictor of intense LBP. A culture in the work unit that was perceived as "rather little", "some", "rather much", or "very much" pleasant and relaxing was associated with, or tended to be associated with lower odds of intense LBP than a culture that
Table 3 Baseline characteristics that predicted certified sick leaves ( $>3$ days) attributed to LBP during the successive three months

\begin{tabular}{|c|c|}
\hline Characteristics at baseline & Odds ratio $(95 \% \mathrm{Cl})$ \\
\hline \multicolumn{2}{|l|}{ Quantitative work demands } \\
\hline 1 (lowest quintile) & 1.00 \\
\hline 2 & 1.21 (0.58 to 2.51$)$ \\
\hline 3 & $2.27(1.32$ to 3.90$)$ \\
\hline 4 & $1.23(0.68$ to 2.24$)$ \\
\hline 5 & $1.61(0.86$ to 3.01$)$ \\
\hline \multicolumn{2}{|c|}{$\begin{array}{l}\text { Supportive and encouraging culture in the } \\
\text { work unit }\end{array}$} \\
\hline Not at all, very little, or rather little & 1.00 \\
\hline Some & $0.49(0.27$ to 0.90$)$ \\
\hline Rather much & $0.43(0.24$ to 0.77$)$ \\
\hline Very much & $0.46(0.25$ to 0.86$)$ \\
\hline \multicolumn{2}{|l|}{ Fatigue/fitness } \\
\hline Always or usually fit & 1.00 \\
\hline Varied between fit and fatigued & $1.27(0.82$ to 1.96$)$ \\
\hline Usually or always fatigued & $1.96(1.13$ to 3.38$)$ \\
\hline \multicolumn{2}{|l|}{$\begin{array}{l}\text { Have ever changed work or work tasks } \\
\text { because of pain }\end{array}$} \\
\hline No & 1.00 \\
\hline Yes & 1.62 (1.02 to 2.59$)$ \\
\hline \multicolumn{2}{|l|}{ LBP previous 3 months } \\
\hline No & 1.00 \\
\hline Yes & 1.68 (1.15 to 2.47$)$ \\
\hline
\end{tabular}

The final equation in a forward stepwise logistic regression analysis, with likelihood ratio test used as the criterion for determining variables to be removed from the model. $n=3283$.

The overall rate of correct classification of the dependent variable (predicted outcome compared with the observed outcome) was estimated as $96.16 \%$.

The factors not retained in the final equation were age, gender, number of preschool children, engagement in special tasks caring nature in the leisure time, intensity of musculoskeletal pain (any), level of affective symptoms, sleep complaints, widespread pain, long term health problems of any kind, working in a somatic hospital department, level of role conflicts at work, the extent of pleasant and relaxing culture in the work unit, rewards for good work, and level of commitment to the work unit.

was perceived as "not at all or very little" pleasant and relaxing.

\section{Predictors of LBP related sick leave; multivariate analyses}

Forward stepwise logistic regression analyses also revealed the following associations. LBP related sick leaves exceeding three days were predicted by medium level of quantitative work demands, prior changes of work or work tasks because of pain, LBP during the three months prior to baseline, and having usually or always felt fatigued during the 14 days prior to baseline (table 3). A culture in the work unit that was perceived as "some", "rather much", or "very much" supportive and encouraging was associated with lower odds of LBP related sick leaves exceeding three days than a culture that was perceived as "not at all, very little, or rather little" supportive and encouraging.

LBP related sick leaves exceeding 14 days were predicted by working in a nursing home, working sometimes or very often night shifts, changes of work or work tasks during the 15 month observation period that resulted in reduced perceived support and encouragement at work, prior changes of work or work tasks because of pain, LBP during the three months prior to baseline, and intense musculoskeletal pain of any kind during the 14 days prior to baseline (table 4).

LBP related sick leaves exceeding eight weeks were predicted by handling heavy objects five times or more per average shift, changes of work or work tasks during the 15 month observation period that resulted in reduced perceived support and encouragement at work, LBP during the three months prior to baseline, and intense musculoskeletal pain of any kind during the 14 days prior to baseline (table 5). 
Table 4 Factors that predicted sick leaves longer than 14 days attributed to LBP during the 12 months prior to the 15 month follow up

\begin{tabular}{|c|c|}
\hline Characteristics & Odds ratio $(95 \% \mathrm{Cl})$ \\
\hline \multicolumn{2}{|c|}{ Working in a nursing home } \\
\hline No & 1.00 \\
\hline Yes & 1.38 (1.01 to 1.88$)$ \\
\hline \multicolumn{2}{|c|}{ Working night shifts } \\
\hline Never & 1.00 \\
\hline Sometimes & $1.52(1.06$ to 2.19$)$ \\
\hline Rather often & $1.39(0.73$ to 2.63$)$ \\
\hline Very often & 1.64 (1.09 to 2.49$)$ \\
\hline \multicolumn{2}{|c|}{$\begin{array}{l}\text { Change of work or work tasks between } \\
\text { baseline and the follow up that resulted in } \\
\text { reduced support and encouragement at work }\end{array}$} \\
\hline No & 1.00 \\
\hline Yes & 2.79 (1.25 to 6.25$)$ \\
\hline \multicolumn{2}{|c|}{$\begin{array}{l}\text { Have ever changed work or work tasks } \\
\text { because of pain }\end{array}$} \\
\hline No & 1.00 \\
\hline Yes & $1.77(1.20$ to 2.61$)$ \\
\hline \multicolumn{2}{|c|}{ LBP during the 3 months prior to baseline } \\
\hline No & 1.00 \\
\hline Yes & $2.23(1.58$ to 3.14$)$ \\
\hline \multicolumn{2}{|c|}{ Intensity of musculoskeletal pain (any) } \\
\hline No & 1.00 \\
\hline A little & $1.85(0.86$ to 3.94$)$ \\
\hline Rather intense & 2.91 (1.35 to 6.26$)$ \\
\hline Very intense & 3.56 ( 1.58 to 8.05$)$ \\
\hline
\end{tabular}

The final equation in a forward stepwise logistic regression analysis, with likelihood ratio test used as the criterion for determining variables to be removed from the model. $n=2907$

The overall rate of correct classification of the dependent variable (predicted outcome compared with the observed outcome) was estimated as $93.70 \%$.

The factors not retained in the final equation were age, gender, level of affective symptoms, sleep complaints, fatigue, long term health problems of any kind, frequency of positioning patients in bed, frequency of handling heavy objects at work, quantitative work demands, positive challenges at work, level of influence on decisions at work, level of control over work pace, level of role conflicts at work, level of support from immediate superior, fairness of the immediate superior's leadership, the extent of supportive and encouraging culture in the work unit, the extent of pleasant and relaxing culture in the work unit, rewards for good work, exposure to threats and violence at work, level of commitment to the work unit, and level of perceived mastery of work.

\section{DISCUSSION}

In this prospective study of Norwegian nurses' aides who at the outset were not, or only a little bothered by LBP, frequent positioning of patients in bed, frequent handling of heavy objects at work, medium level of work demands, perceived lack of support from superior, perceived lack of a pleasant and relaxing or supporting and encouraging culture in the work unit, working in a nursing home, and working night shifts predicted intense low back symptoms or LBP related sick leaves.

\section{Methodological considerations}

The response rate in the first data collection was moderate. Hence, selection bias may have influenced the results. The number of dropouts between baseline and the follow ups was low, but there were some differences between the responders and the dropouts. It is not likely, though, that selection bias due to withdrawal between baseline and the follow ups explains the main findings in this study.

A healthy worker selection, ${ }^{21}$ due to the fact that unhealthy persons have avoided specific high exposure jobs or changed to lower exposure jobs prior to the data collection, may cause interpretation problems in studies of occupational populations. The result may be an underestimation of associations between work factors or high exposure categories of work factors and health related outcomes. In the present study, the impact of this healthy worker effect has probably been
Table 5 Factors that predicted sick leaves longer than eight weeks attributed to LBP during the 12 months prior to the 15 month follow up

\begin{tabular}{|c|c|}
\hline Characteristics & Odds ratio $(95 \% \mathrm{Cl})$ \\
\hline \multicolumn{2}{|c|}{$\begin{array}{l}\text { Liffing, carrying, and pushing heavy objects } \\
\text { at work (per average shift) }\end{array}$} \\
\hline 0 & 1.00 \\
\hline $1-4$ & 0.99 (0.59 to 1.64$)$ \\
\hline $5-9$ & $2.21(1.17$ to 4.16$)$ \\
\hline$\geqslant 10$ & $2.20(0.94$ to 5.10$)$ \\
\hline \multicolumn{2}{|c|}{$\begin{array}{l}\text { Change of work or work tasks between } \\
\text { baseline and the follow up that resulted in } \\
\text { reduced support and encouragement at } \\
\text { work }\end{array}$} \\
\hline No & 1.00 \\
\hline Yes & 4.14 (1.68 to 10.24$)$ \\
\hline \multicolumn{2}{|c|}{ LBP previous 3 months } \\
\hline No & 1.00 \\
\hline Yes & 2.08 (1.32 to 3.28$)$ \\
\hline \multicolumn{2}{|c|}{ Intensity of musculoskeletal pain (any) } \\
\hline No & 1.00 \\
\hline A little & 1.98 (0.69 to 5.73 ) \\
\hline Rather intense & $3.32(1.15$ to 9.63$)$ \\
\hline Very intense & 4.24 (1.38 to 12.97$)$ \\
\hline \multicolumn{2}{|c|}{$\begin{array}{l}\text { The final equation in a forward stepwise logistic regression analysis, with } \\
\text { likelihood ratio test used as the criterion for determining variables to be } \\
\text { removed from the model. } n=2929 \text {. } \\
\text { The overall rate of correct classification of the dependent variable } \\
\text { (predicted outcome compared with the observed outcome) was estimatec } \\
\text { as } 96.62 \% \text {. } \\
\text { The factors not retained in the final equation were age, gender, having } \\
\text { ever changed work or work tasks because of pain, level of affective } \\
\text { symptoms, sleep complaints, fatigue, widespread pain, long term health } \\
\text { problems of any kind, frequency of liffing and supporting patients } \\
\text { manually between bed and chair, quantitative work demands, level of } \\
\text { influence on decisions at work, level of control over work pace, level of } \\
\text { role conflicts at work, fairness of the immediate superior's leadership, the } \\
\text { extent of suspicious culture in the work unit, and exposure to bullying a } \\
\text { work. }\end{array}$} \\
\hline
\end{tabular}

reduced by the prospective design, and by adjustments for LBP during the three months prior to baseline, baseline health complaints, and prior changes of work or work tasks because of pain. However, the effect may not have been removed completely; in several analyses, medium level categories, such as medium level of work demands and medium frequency of patient handling, showed stronger associations with the outcomes than the factors' high exposure categories.

Differential exposure to physical and psychosocial factors prior to the first survey may have influenced the results. So may prior LBP.

The time limit for the first follow up was only three months, which is a short time for tracing causal effects. On the other hand, short observation periods may also have positive aspects, such as few dropouts, few changes of exposures, and low recall bias.

Self reporting of LBP during the previous seven days and during the previous 12 months has been reported to have good reliability in test-retests, and good agreement has been found between information given in self administered questionnaires and information given in interviews and clinical examinations. ${ }^{22}{ }^{23}$ The memory of pain intensity seems to be good, at least for the previous two weeks. ${ }^{24} 25$ Studies have shown high agreement between information from official registers and self reported certified spells of LBP related sickness absence. ${ }^{26} 27$

Some authors have found high correlations ${ }^{28}$ and others have found fair or modest correlations ${ }^{29} 30$ between "objective" and self reported information on psychosocial work environment. Few psychological aspects of the work situation may be measured objectively, though. Intermethod surveys indicate that self reports have acceptable validity for gross 
activities in the job. ${ }^{18} 3132$ The questions in the present study that were used to assess the frequency of patient handling were found to have good validity in a British study. ${ }^{18}$ The scales that were used to measure psychosocial and organisational work factors have been found to have good construct and predictive validity as well as good internal consistency and test-retest reliability. ${ }^{19}$

Workers with health problems are probably more likely than other persons to perceive aspects of their work as strenuous or problematic. ${ }^{32}$ This problem was taken into account by adjusting for the severity of common health complaints at the time the work factors were recorded.

\section{Predictors of intense LBP}

An association between patient handling and LBP has been reported in several studies, ${ }^{67}$ although a recent review, taking into account the quality of the studies, reported only moderate evidence for such an association. ${ }^{7}$ Some studies suggest that positioning patients in bed leads to LBP more often than other manual patient transfer procedures conducted by nurses. ${ }^{33}{ }^{34}$ In the present study, the frequency of positioning patients in bed, but not the frequency of lifting and supporting patients manually between bed and chair, predicted intense LBP.

There seems to be evidence for low social support at work as a risk factor of LBP. $^{8}$ The extent to which low social support at work is related to LBP in nursing personnel is not clear, though. In a cross-sectional study of 90 Swedish nurses, no association was found between social support at work and LBP after adjustments for other work factors. ${ }^{35}$ In a cross-sectional study of 688 nurses at a hospital in Sweden, low support from superiors was associated with low back symptoms, but not with severe low back symptoms. ${ }^{4}$ In the present study, perceived lack of support from the immediate superior predicted intense LBP.

Few studies have explored how the organisational culture of the work unit-that is, the behavioural and attitudinal characteristics of the people in the work organisation, ${ }^{36}$ is related to the occurrence of LBP. In the present study, perceived lack of a pleasant and relaxing culture in the work unit predicted intense LBP. Further research is needed to confirm the finding.

There is sparse knowledge of how engagement in tasks of a caring nature during leisure time is related to the risk of LBP. Some studies have shown lacking or negative associations between the number of children and LBP in nursing personnel. ${ }^{18} 37$ In the present study, having one preschool child and being much engaged in other tasks of a caring nature in the leisure time, such as caring for handicapped children or elderly relatives, predicted intense LBP. The fact that one preschool child, and not two or more children, was associated with an increased risk, may be due to a selection effect. Individuals with long term health problems may experience problems combining paid work with family obligations, and, hence, withdraw from the labour force or refrain from having several children.

Not only LBP, but also pain in other regions of the body and widespread pain were predictors of intense LBP. Other studies show that persons with LBP who also have widespread pain differ from persons with LBP as the only complaint, with respect to demographic characteristics, functional ability, and prognosis. ${ }^{38} 39$ The LBP that is seen in general pain syndromes may represent a specific entity. Fatigue was also a predictor of intense LBP, whereas Smedley et al found no significant association between fatigue and LBP in British nurses. ${ }^{11}$

\section{Predictors of LBP related sick leave}

Evidence for an association between material handling and LBP related sickness absence has been found in several occupational groups. ${ }^{10}{ }^{15}$ In Dutch workers, Hoogendoorn et al found that frequent heavy lifting at work was a strong predictor of LBP related sickness absence exceeding seven days, but not a predictor of short term LBP related sick leaves. ${ }^{15}$ In the present study, the frequency of lifting, carrying, and pushing heavy objects predicted LBP related sick leaves exceeding eight weeks, but not LBP related sick leaves of shorter duration.

In their prospective study of Dutch workers, Hoogendoorn et al found no association between quantitative work demands and LBP related sickness absence. ${ }^{15}$ In the present study, a medium level of quantitative work demands predicted LBP related sick leaves. Healthy worker selection could explain why respondents reporting a medium level of quantitative work demands had a higher risk than respondents reporting the highest level.

Low social support at work has been reported to predict LBP related sickness absence in US soldiers ${ }^{14}$ and in employees at two metal industry companies, ${ }^{12}$ but was not a convincing predictor of back pain related sick leaves in Dutch workers ${ }^{15}$ and British civil servants. ${ }^{16}$ In the present study, a perceived lack of encouraging and supportive culture in the work unit predicted LBP related sick leaves. Moreover, changes of work or work tasks during the observation period, resulting in reduced support and encouragement at work, were associated with long term LBP related sick leaves.

The relation between night shift work and the occurrence of LBP in nursing personnel has been explored in a few crosssectional studies. ${ }^{37} 40$ A non-significant tendency for more LBP in personnel who were working night shifts was found in one of the studies. ${ }^{40}$ In the present study, aides who reported at least some night shift work had higher risk of LBP related sick leaves than those who were never working night shifts. One explanation may be that few personnel are present at work during night shifts, leaving the aides often alone with heavy patient transfer procedures.

Working in a nursing home was associated with an increased risk of LBP related sick leave, even after adjustments for specific work factors. One explanation may be that many patients in nursing homes are bed-ridden and helpless, and, hence, represent a major physical challenge to nursing personnel in connection with manual patient transfer procedures. Others studied hospital nurses, and found a higher occurrence of back pain in orthopaedic, neurological, and medical wards than in paediatric, psychiatric, and gynaecological wards. ${ }^{41} 42$

In agreement with other studies, ${ }^{11}{ }^{13} 43$ prior LBP predicted LBP related sick leaves. In contrast to a study of British nurses, ${ }^{11}$ fatigue predicted LBP related sick leaves.

\section{Confounding}

The results may have been influenced by background factors for which we were not able to control. Among the potential confounders are psychological trait factors, such as hostility, locus of control, poor self esteem, and unrealistic expectations about work and colleagues, ${ }^{44}{ }^{45}$ and lifestyle factors other than smoking and exercise, such as alcohol consumption. $^{46}$ These individual-level factors could influence the reporting of work factors as well as the perceptions of symptoms and the decisions to be absent from work.

\section{Conclusions}

Not only frequent mechanical exposures, but also organisational, psychological, and social work factors, such as night shift work, perceived lack of support from superior, and perceived lack of a pleasant and relaxing or supporting and 
encouraging culture in the work unit, are associated with an increased risk of intense low back symptoms and LBP related sick leaves in nurses' aides.

\section{ACKNOWLEDGEMENTS}

This study was supported financially by the Norwegian Research Council, EXTRA funds from the Norwegian Foundation for Health and Rehabilitation fund, The Norwegian Ministry of Health and Social Affairs, Rhône-Poulenc Rorer Ltd, Peter Møller AS, and Dr Trygve Gythfeldt Research Fund.

\section{Authors' affiliations}

W Eriksen, D Bruusgaard, Department of General Practice and Community Medicine, University of Oslo, Oslo, Norway

S Knardahl, National Institute of Occupational Health, Oslo, Norway; Department of Psychology, University of Oslo, Oslo, Norway

\section{REFERENCES}

1 Frank JW, Kerr MS, Brooker A-S, et al. Disability resulting from occupational low back pain. Part I: What do we know about primary prevention? A review of the scientific evidence on prevention before disability begins. Spine 1996;21:2908-17.

2 Estryn-Behar M, Kaminski M, Peigne E, et al. Strenuous working conditions and musculo-skeletal disorders among female hospital workers. Int Arch Occup Environ Health 1990;62:47-57.

3 Fuortes $L$, Shi $Y$, Zhang $M$, et al. Epidemiology of back injury in university hospital nurses from review of workers' compensation records and a casecontrol survey. J Occup Med 1994;36:1022-6.

4 Lagerström $M$, Wenemark $M$, Hagberg $M$, et al. Occupational and individual factors related to musculoskeletal symptoms in five body regions among Swedish nursing personnel. Int Arch Occup Environ Health 1995;68:27-35

5 Burdorf A, Sorock G. Positive and negative evidence of risk factors for back disorders. Scand J Work Environ Health 1997;23:243-56.

6 Lagerström M, Hansson T, Hagberg M. Work-related low-back problems in nursing. Scand J Work Environ Health 1998;24:449-64.

7 Hoogendoorn WE, van Poppel MNM, Bongers PM, et al. Physical load during work and leisure time as risk factors for back pain. Scand J Work Environ Health 1999;25:387-403

8 Hoogendoorn WE, van Poppel MNM, Bongers PM, et al. Systematic review of psychosocial factors at work and private life as risk factors for back pain. Spine 2000;25:2114-25.

9 Boshuizen HC, Hulshof CTJ, Bongers PM. Long-term sick leave and disability pensioning due to back disorders of tractor drivers exposed to whole-body vibration. Int Arch Occup Environ Health 1990;62:117-22.

10 Nuwayhid IA, Stewart W, Johnson JV. Work activities and the onset of firsttime low back pain among New York city firefighters. Am J Epidemiol 1993; 137:539-48.

11 Smedley J, Egger P, Cooper C, et al. Prospective cohort study of predictors of incident low back pain in nurses. BMJ 1997:314:1225-8.

12 Wickstrom GJ, Pentti J. Occupational factors affecting sick leave attributed to low-back pain. Scand J Work Environ Health 1998;24:145-52.

13 Müller CF, Monrad T, Biering-Sørensen F. The influence of previous low back trouble, general health, and working conditions on future sick-listing because of low back trouble. A 15-year follow-up study of risk indicators for selfreported sick-listing caused by low back trouble. Spine 1999;24:1562-70.

14 Feuerstein M, Berkowitz SM, Huang GD. Predictors of occupational low back disability: implications for secondary prevention. J Occup Environ Med 1999:41:1024-31.

15 Hoogendoorn WE, Bongers PM, de Vet HCW, et al. High physical work load and low job satisfaction increase the risk of sickness absence due to low back pain: results of a prospective cohort study. Occup Environ Med 2002;59:323-8.

16 Hemingway $\mathbf{H}$, Shipley MJ, Stansfeld S, et al. Sickness absence from back pain, psychosocial work characteristics and employment grade among office workers. Scand J Work Environ Health 1997;23:121-9.

17 Eriksen W, Bruusgaard D. Physical leisure-time activities and long-term sick leave: A 15-month prospective study of nurses' aides. J Occup Environ Med 2002;44:530-8.
18 Smedley J, Egger P, Cooper C, et al. Manual handling activities and risk of low back pain in nurses. Occup Environ Med 1995;52:160-3.

19 Dallner M, Elo A-L, Gamberale F, et al. Validation of the General Nordic Questionnaire (QPSNordic) for Psychological and Social Factors at Work. Nord 2000;12.

20 Hosmer DW, Lemeshow D. Applied logistic regression. John Wiley \& Sons, 1989.

21 Kraus JF, Gardner L, Collins J, et al. Design factors in epidemiologic cohort studies of work-related low back injury or pain. Am J Ind Med 1997:32:153-63.

22 Holmström E, Moritz U. Low back pain-correspondence between questionnaire, interview and clinical examination. Scand J Rehabil Med 1991;23:119-25.

23 Walsh K, Coggon D. Reproducibility of histories of low back pain obtained by self- administered questionnaire. Spine 1991;16:1075-7.

24 Jensen MP, Turner LR, Turner JA, et al. The use of multiple-item scales for pain intensity measurement in chronic pain patients. Pain 1996;67:35-40.

25 Salovey P, Smith AF, Turk DC, et al. The accuracy of memory for pain: not so bad most of the time. Am Pain Soc J 1993:2:184-91.

26 Fredriksson K, Toomingas A, Torgen $M$, et al. Validity and reliability of selfreported retrospectively collected data on sick leave related to musculoskeleta diseases. Scand J Work Environ Health 1998;24:425-31.

27 Burdorf A, Post W, Bruggeling T. Reliability of a questionnaire on sickness absence with specific attention to absence due to back pain and respiratory complaints. Occup Environ Med 1996;53:58-62.

28 Karasek R, Theorell T. Healthy work. Stress, productivity, and the reconstruction of working life. New York: Basic Books, 1990:80.

29 North FM, Syme SL, Feeney A, et al. Psychosocial work environment and sickness absence among British civil servants: The Whitehall II study. Am J Public Health 1996;86:332-40.

30 Spector PE, Jex SM. Relations of job characteristics from multiple data sources with employee affect, absence, turnover intentions, and health. J Appl Psychol $1991 ; 76: 46-53$.

31 Burdorf A. Reducing random measurement error in assessing postural load on the back in epidemiologic surveys. Scand J Work Environ Health 1995;21:15-23.

32 Viikari-Juntura E, Rauas S, Martikainen R, et al. Validity of self-reported physical work load in epidemiologic studies on musculoskeletal disorders. Scand J Work Environ Health 1996;22:251-9.

33 Cato C, Olson D, Studer M. Incidence, prevalence, and variables associated with low back pain in staff nurses. AAOHN J 1989:3:321-7.

34 Leighton DJ, Reilly T. Epidemiological aspects of back pain: the incidence and prevalence of back pain in nurses compared to the general population. Occup Med 1995;45:263-7

35 Ahlberg-Hultén GK, Theorell T, Sigala F. Social support, job strain and musculoskeletal pain among female health care personnel. Scand J Work Environ Health 1995;21:435-9.

36 Schein E. Organizational culture. American Psychologist 1990;45:109-19.

37 Niedhammer I, Lert F, Marne MJ. Back pain and associated factors in French nurses. Int Arch Occup Environ Health 1994:66:349-57.

38 Natvig B, Bruusgaard D, Eriksen W. Localised low back pain and low back pain as part of widespread musculoskeletal pain; two different disorders? A cross-sectional population study. Scand J Rehab Med 2001;33:21-5.

39 Natvig B, Eriksen W, Bruusgaard D. Low back pain as predictor of long-term work disability. A 4-year prospective study. Scand J Public Health 2002;30:288-92.

40 Josephson M, Vingård E, MUSIC-Norrtälje Study Group. Workplace factors and care seeking for low-back pain among female nursing personnel. Scand J Work Environ Health 1998;24:465-72.

41 Venning PJ, Walter SD, Stitt LW. Personal and job-related factors as determinants of incidence of back injuries among nursing personnel. $J$ Occup Med 1987;29:821-5

42 Yassi A, Khokar J, Tate R, et al. The epidemiology of back injuries in nurses at a large Canadian tertiary care hospital: implications for prevention. Occup Med 1995:45:215-20.

43 Van Poppel MNM, Koes BW, Devillé W, et al. Risk factors for back pain incidence in industry: a prospective study. Pain 1998;77:81-6.

44 Parkes KR. Locus of control as moderator: an explanation for additive versus interactive findings in the demand-discretion model of work stress? Br J Psychol 1991;82:291-312

45 Vahtera J, Kivimäki M, Uutela A, et al. Hostility and ill health: role of psychosocial resources in two contexts of working life. J Psychosom Res 2000;48:89-98

46 Marmot MG, North F, Feeney A, et al. Alcohol consumption and sickness absence: from the Whitehall II study. Addiction 1993;88:369-82. 